\title{
Performing comparative determinations on pollutant immissions through reference methods and by means of infrared spectroscopy
}

\author{
Lorand Toth*, Angelica Călămar, Alexandru Simion, and Alin Irimia \\ National Institute for Research and Development in Mine Safety and Protection to Explosion - \\ INSEMEX, 32-34 G-ral Vasile Milea, Petrosani, Romania
}

\begin{abstract}
Atmospheric pollutants come from a series of anthropic activities and natural processes. When feeding large amounts of polluting species into the atmospheric layer, the issue of air pollution phenomenology is stated. Atmospheric pollution implies a risk generated by exposure to harmful substances (under different forms of aggregation) for all living organisms in the biosphere. This paper aims to identify the possibility of using an alternative method of determining air quality compared to currently used reference methods. There is the question of checking through statistical tools of the advantage of using a single determination to obtain the pollutant species and the gas concentrations Currently, carbon oxide concentration is determined by non-dispersive IR spectroscopy, nitrogen oxides are determined by chemiluminescence and sulphur dioxide is determined by UV fluorescence, these being the reference methods. For the achievement of highlighting results, the gas concentrations will be determined both by the reference methods and by an alternative method involving Fourier-transform infrared spectroscopy, imposing on the alternative method quality assurance criteria. By knowing the pollutant levels, can develop various air pollution control technologies and strategies in order to reduce air pollution, also design effective and economically efficient air pollution control strategies for human protection. Expected results involve data processing, obtained from field measurements of polluting species $\left(\mathrm{CO}, \mathrm{NO}_{\mathrm{x}} \mathrm{SO}_{2}\right)$, through statistical instruments (repeatability / reproducibility limit, bias, accuracy and uncertainty of measurement) and establishing the framing of the results in the performance requirements imposed by the specialized literature in order to use modern methods for quantifying the level of air pollution.
\end{abstract}

\section{Introduction}

Atmospheric pollution endangers the health of the entire biosphere. Due to massive refurbishment and the choice of best available techniques at European Communities level,

\footnotetext{
* Corresponding author: lorand.toth@insemex.ro
} 
it was possible to reduce certain concentrations of polluting species allowing a deceleration of air pollution phenomena [1,2]. Following steps and efforts made, there still are exceedances of some air pollutant concentrations in certain areas. European urban agglomerations are still experiencing adverse effects caused by air pollution by carbon dioxide, nitrogen oxides and sulphur dioxide which pose serious health risks In 2015, several countries exceeded one or more limits for certain air pollutant species. The reduction of air pollution is therefore important. Because of slow or less optimal implementation of air purification systems, the phenomenon of air pollution persists, if we refer to guidelines of forums in the field of environmental protection. Atmosphere contamination with different polluting species has as a consequence a negative impact on the environment's biotic component [3]. The anthropic activity generated by industrial development has a negative influence on cities and urban communities. Air pollution also has a considerable impact on the economy, reducing life span, emphasizing the implications in the medical field as well as decelerating the positive economic rate as a result of the number of working days lost because of health problems [4].

The phenomena of atmospheric pollution entail negative aspects on the ecosystems because it degrades soils, forests, lakes and rivers and reduces agricultural production. Maintaining an environment favourable for the biosphere, is achieved by implementing a unitary vision at micro and macro local level, where atmospheric pollutant emissions are retained and purified at the source. As a result, atmospheric pollution must be reduced and clear objectives regarding preserving a high ambient air quality maintained [5].

\section{Methods for measuring gaseous immissions in atmosphere}

The transport, diffusion and transformation of pollutants into the atmosphere (transmission) from source to receiver is accomplished by physical and chemical processes that are inherent to the atmosphere in the boundary layer, which implies knowledge of the transport, diffusion and transformation mechanisms, as well as of the atmospheric factors involved. Immissions, i.e. the temporal-space distribution and the concentration of pollutants in the atmosphere, are monitored by measurements (and mathematical modelling) of concentrations in order to gather data regarding the state and evolution of air quality [6]. The objectives of immissions monitoring derive from the need to be aware of the status and the evolution of concentrations related to a clean air [7].

\subsection{The measurement of carbon monoxide concentration in the environmental atmosphere}

Immissions of $\mathrm{CO}$ concentration are measured in accordance with the standard method: SR EN 14626:2012 - Ambient air. Standardized method for measuring carbon monoxide concentration by non-dispersive infrared spectroscopy. Quantification of the CO level can be obtained by applying the Lambert-Beer law, with the help of a light beam in the IR field [8]. The measurement of $\mathrm{CO}$ concentration is also influenced by the existence of heteroatomic molecules that will absorb infrared light $(\mathrm{H} 2 \mathrm{O}$ and $\mathrm{CO} 2)$, which can lead to interference. Various technical solutions have been adopted in order to minimize / eliminate cross-sensitivity, the instability of the measurement flow as well as the drift, thus obtaining very stable CO continuous monitoring equipment [8].

CO measurements were performed using the APMA 370 carbon oxide analyser using infrared absorption non-dispersive detection to carry out a continuous carbon dioxide analysis in the $0-100$ ppm range with auto scale. 


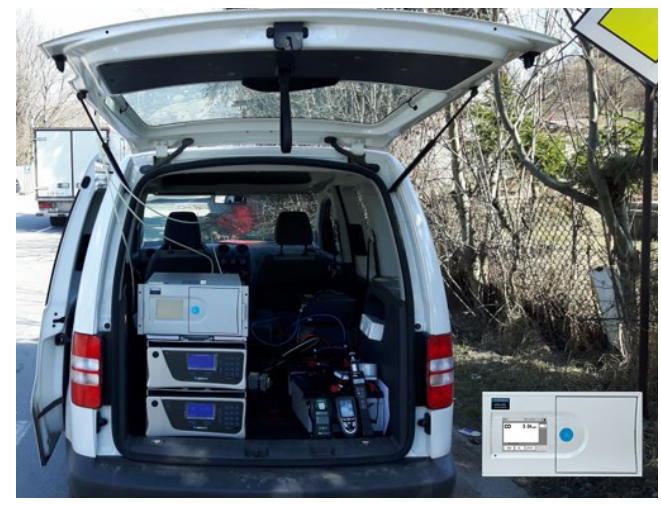

Fig. 1. Mobile laboratory - CO Analyser, APMA 370 Model

\subsection{The measurement of nitrogen oxide species concentration in the environmental atmosphere}

Immissions of NOx concentration are measured in accordance with the standard method: SR EN 14211:2012 Ambient air. Standardized method for measuring the concentration of nitrogen nitrogen oxide species by chemiluminescence [9]. Chemiluminescence is based on the reaction of nitrogen monoxide with ozone. In a chemiluminescence based analyser, the air is drawn through a filter (in order to prevent the contamination of the transport system, in particular the analyser's optical components) and fed at a slow flow rate to the analyser reaction chamber (where it is mixed with an ozone excess) for the testing of nitrogen monoxide alone [9]. The chemiluminescence phenomena is direct scaled with the number of molecules of nitrogen monoxide in the detection volume and thus proportional to the concentration of nitrogen monoxide [9].

For the measurement of nitrogen dioxide, the extracted air is fed through a converter where the nitrogen dioxide is reduced to nitrogen monoxide and analysed. The electrical signal obtained from the photomultiplier (photodiode tube) is direct scaled with the sum of the concentrations of nitrogen oxide species [9].

During the gaseous phase of the NO and ozone reaction, light is produced with a proportional $\mathrm{NO}$ concentration when the electrons of activated $\mathrm{NO}_{2}$ molecules disintegrate at lower energy states.

The Serinus 40 Nitrogen Oxide Analyzer uses gas phase chemiluminescence detection to carry out a continuous analysis of nitrogen oxide, total nitrogen oxides and nitrogen dioxide in the range of $0-1000 \mathrm{ppb}(\mathrm{NO}) ; 0-260 \mathrm{ppb}\left(\mathrm{NO}_{2}\right)$

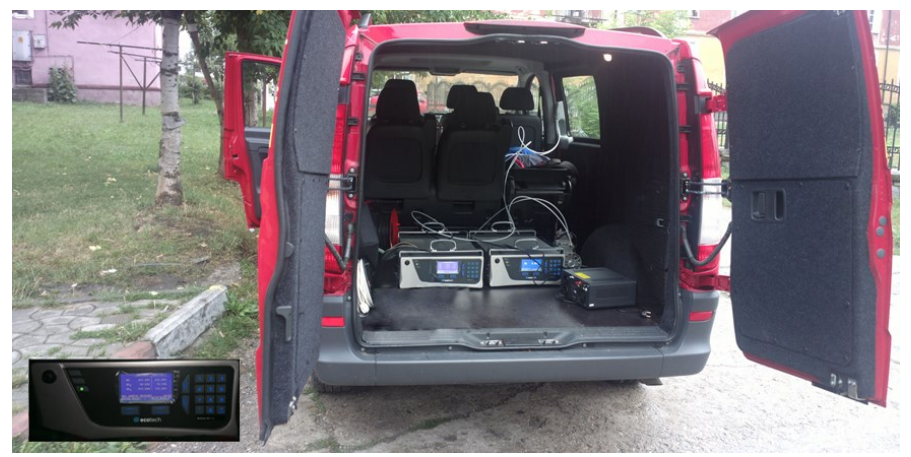

Fig. 2. Mobile laboratory - $\mathrm{NO} / \mathrm{NO}_{2} / \mathrm{NO}_{\mathrm{X}}$ Analyzer, Ecotech Serinus 40 Model 


\subsection{The measurement of sulphur dioxide concentration in the environmental atmosphere}

Immissions of NOx concentration are measured in accordance with the standard method: SR EN 14212:2012 - 120/5000 Ambient air. Standardized method for measuring the concentration of sulphur dioxide by ultraviolet fluorescence. Fluorescence is a phenomenon of photoluminescence that involves generating an initial absorption phenomenon. Luminescent molecules excited by some quantum states (in this case irradiation in the ultraviolet field) remain in this state for at least $10^{-9}$ seconds, after which returns to the fundamental state by luminous emission [10]. This secondary emission is related to the $\mathrm{SO}_{2}$ molecules in the sample and captured, transformed and transmitted as an electrical signal by the photomultiplier tube (PMT) of the apparatus.

The fluorescence phenomenon occurs when the molecule, at a certain level of energy, possesses at least two distinct electronic states whose level of rotation-vibration intersects in a way that is at least one vibration rotation level of the same energy value, in each state.

The Ecotech Serinus 50 sulphur dioxide analyser uses ultraviolet fluorescence detection to conduct continuous analysis in the 0 to $20 \mathrm{ppm}$ range with auto scale.

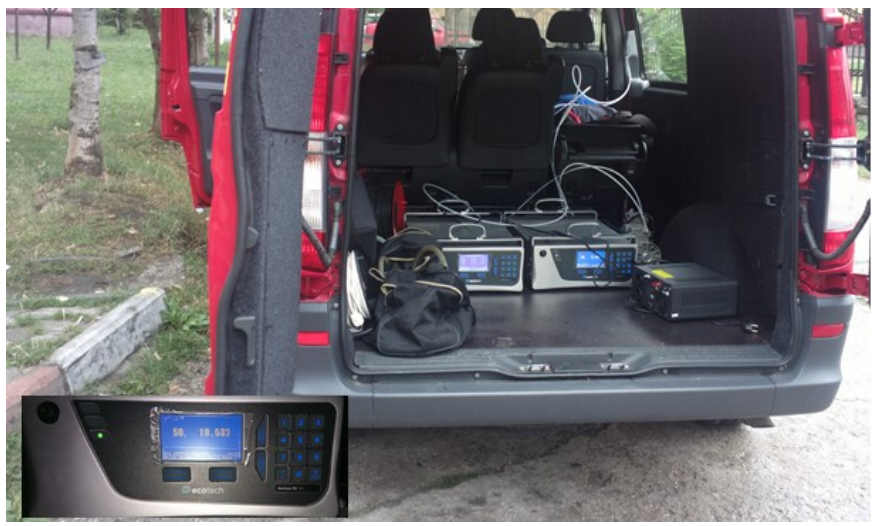

Fig. 3. Mobile laboratory - $\mathrm{SO}_{2}$ Analyzer, Ecotech Serinus 50 Model

\subsection{The measurement of gaseous immissions through Fourier Transform Infrared spectroscopy (FTIR)}

Broadly speaking, the FTIR spectrometer is composed of a beam splitter as well as a set of moving mirrors. Due to the mirrors, the two beams produced have a phase difference and recombined the produced IR intensity scales with the mirror position. The interferometer is an optical modulator which allowing to calculate the intensity at each frequency from the signal recorded by IR detector [11].

The IR detector records a signal given by a function of time or mirror position obtaining a interferogram [11]. By placing a sample cell between the interferometer and the detector, the spectrometer can be used to measure a sample gas absorption spectrum, and the identity and concentration of the sample gases can be calculated from the absorption spectrum. [11]. 


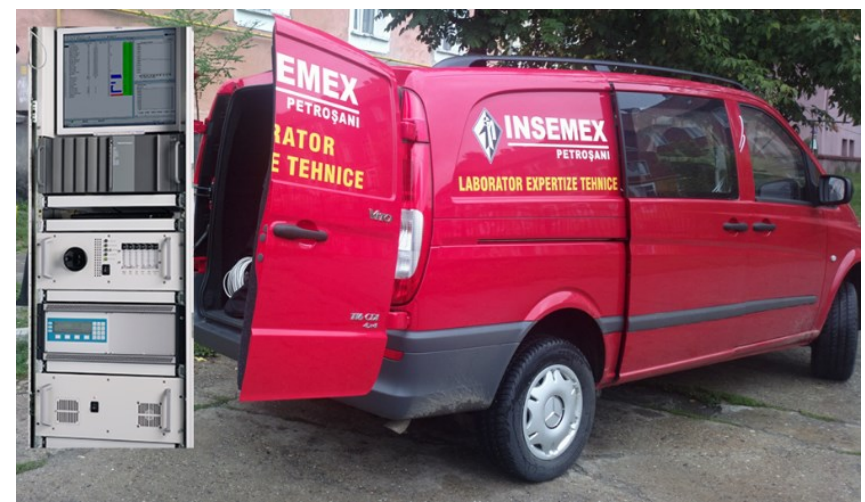

Fig. 4. Mobile laboratory - Continuous Emission Monitoring System CEMS II Analyzer, Gasmet Model

\section{Results and discussion}

For the verification of the comparative measurements, two operators were chosen for the use of measuring equipments. Thus, through statistical tools, we can verify whether the performance criteria are met, which would allow the use of Fourier Transform Infrared spectroscopy (FTIR) technology for qualitative and quantitative measurement of atmospheric pollutants species (immissions). The performance criteria to be used are the repeatability / reproducibility limit, bias, fidelity (accuracy) and uncertainty of measurement. The measurements were carried out in a traffic monitoring area in Petrosani (Hunedoara County). The location where the polluting species were monitored, was the intersection of streets 1 Decembrie 1918 with Nicolae Balcescu street, between 8:00 - 18:00. Only average values of measurements were used in the statistical processing performed and in data presentation.

Table 1. Values, pollutant species and equipments used for measurements

\begin{tabular}{|c|c|c|c|c|c|c|}
\hline \multirow{7}{*}{ 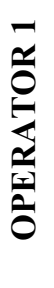 } & Pollutant & Equipment 1 & Equipment 2 & \multirow{7}{*}{ 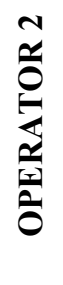 } & Equipment 1 & Equipment 2 \\
\hline & \multirow{2}{*}{$\begin{array}{c}\mathrm{CO} \\
{[\mathrm{mg} / \mathrm{mc}]}\end{array}$} & AMPA 370 & CEMS II & & AMPA 370 & CEMS II \\
\hline & & 9,84 & 10,35 & & 9,96 & 10,51 \\
\hline & \multirow{2}{*}{$\begin{array}{c}\mathrm{NOx} \\
{[\mu \mathrm{m} / \mathrm{mc}]}\end{array}$} & SERINUS 40 & CEMS II & & SERINUS 40 & CEMS II \\
\hline & & 247,5 & 260,7 & & 250,6 & 263,9 \\
\hline & \multirow{2}{*}{$\begin{array}{c}\mathrm{SO}_{2} \\
{[\mu \mathrm{m} / \mathrm{mc}]}\end{array}$} & SERINUS 50 & CEMS II & & SERINUS 50 & CEMS II \\
\hline & & 120,4 & 126,9 & & 121,9 & 128,4 \\
\hline
\end{tabular}

Analysis of performance requirements was determined [6] by calculating the standard deviation, repeatability / reproducibility limit, bias, fidelity and uncertainty of measurement, as follows:

Repeatability limit - the approximation of the agreement between the results of successive measurements performed under identical measurement conditions [12, 13] (Table 2). ( $\mathrm{r}=2,8 * \mathrm{sr}$, where: $\mathrm{sr}$ - standard deviation in repeatability conditions).

Table 2. Repeatability limit values

\begin{tabular}{|l|c|c|}
\hline \multirow{2}{*}{ Concentration } & \multicolumn{2}{|c|}{ Repeatability limit [r] } \\
\cline { 2 - 3 } & Equipment 1 & Equipment 2 \\
\hline $\mathrm{CO}(\mathrm{mg} / \mathrm{mc}): 10$ & 0,15 & 0,17 \\
\hline $\mathrm{NO}_{\mathrm{x}}(\mu \mathrm{m} / \mathrm{mc}): 250$ & 0,8 & 0,9 \\
\hline $\mathrm{SO}_{2}(\mu \mathrm{m} / \mathrm{mc}): 120$ & 0,53 & 0,6 \\
\hline
\end{tabular}

Conclusion: Performance requirement met. 
Reproducibility limit - the obtained values in the same reproducible experiment conditions $[12,13]$. (Table 3$)\left(\mathrm{R}=2,8 * \mathrm{~s}_{\mathrm{R}}\right.$, where: $\mathrm{s}_{\mathrm{R}}-$ standard deviation in repeatability conditions).

Table 3. Reproducibility limit values

\begin{tabular}{|l|c|c|}
\hline \multirow{2}{*}{ Concentration } & \multicolumn{2}{|c|}{ Reproducibility limit [R] } \\
\cline { 2 - 3 } & Equipment 1 & Equipment 2 \\
\hline $\mathrm{CO}(\mathrm{mg} / \mathrm{mc}): 10$ & 0,15 & 0,16 \\
\hline $\mathrm{NO}_{\mathrm{x}}(\mu \mathrm{m} / \mathrm{mc}): 250$ & 8,1 & 8,5 \\
\hline $\mathrm{SO}_{2}(\mu \mathrm{m} / \mathrm{mc}): 120$ & 6,0 & 6,3 \\
\hline
\end{tabular}

Conclusion: Performance requirement met.

Bias - the difference between the obtained value and the reference value $[12,13]$ (Table 4).

$$
\operatorname{bias}(\%)=\frac{\bar{x}-\mu}{\mu} * 100
$$

where: $\bar{x}$ - average value; $\mu$ - reference concentration value

Table 4. Bias

\begin{tabular}{|l|c|c|}
\hline \multirow{2}{*}{ Concentration } & \multicolumn{2}{|c|}{ Bias [\%] } \\
\cline { 2 - 3 } & Equipment 1 & Equipment 2 \\
\hline $\mathrm{CO}(\mathrm{mg} / \mathrm{mc}): 10$ & 1,56 & 3,84 \\
\hline $\mathrm{NO}_{\mathrm{x}}(\mu \mathrm{m} / \mathrm{mc}): 250$ & 0,98 & 4,28 \\
\hline $\mathrm{SO}_{2}(\mu \mathrm{m} / \mathrm{mc}): 120$ & 0,33 & 5,73 \\
\hline
\end{tabular}

Conclusion: Performance requirement met.

Fidelity (accuracy) - covariation [12, 13] (Table 5) calculated by the formula:

$$
\mathrm{CV}=\mathrm{sx} / \mathrm{x}
$$

where: sx - standard deviation of obtained concentration values; $\mathrm{x}$ - reference concentration values.

Table 5. Variation coefficient

\begin{tabular}{|l|c|c|}
\hline \multirow{2}{*}{$\begin{array}{c}\text { Reference concentration } \\
\text { value }\end{array}$} & \multicolumn{2}{|c|}{ Variation coefficient [\%] } \\
\cline { 2 - 3 } & Equipment 1 & Equipment 2 \\
\hline $\mathrm{CO}(\mathrm{mg} / \mathrm{mc}): 10$ & 5,05 & 6,05 \\
\hline $\mathrm{NO}_{\mathrm{x}}(\mu \mathrm{m} / \mathrm{mc}): 250$ & 11,4 & 12,6 \\
\hline $\mathrm{SO}_{2}(\mu \mathrm{m} / \mathrm{mc}): 120$ & 17,8 & 18,8 \\
\hline
\end{tabular}

Conclusion: The fidelity criterion is checked for Variation coefficient $<20 \%$

Measurement uncertainty - the expression of standard deviation of the values [12, 13] (Table 6) attributed to measured quantities.

\begin{tabular}{|c|c|c|c|c|c|c|c|c|c|c|}
\hline \multirow{5}{*}{$\overrightarrow{0}$} & \multirow{2}{*}{$\begin{array}{c}\text { Reference } \\
\text { concentration }\end{array}$} & \multicolumn{2}{|c|}{$\begin{array}{l}\text { Composed } \\
\text { uncertainty }\end{array}$} & \multicolumn{2}{|c|}{$\begin{array}{c}\text { Extended } \\
\text { uncertainty }\end{array}$} & \multirow{5}{*}{ ڤิ } & \multicolumn{2}{|c|}{$\begin{array}{l}\text { Composed } \\
\text { uncertainty }\end{array}$} & \multicolumn{2}{|c|}{$\begin{array}{l}\text { Extended } \\
\text { uncertainty }\end{array}$} \\
\hline & & $\mathrm{EQ}_{1}$ & $\mathrm{EQ}_{2}$ & $\mathrm{EQ}_{1}$ & $\mathrm{EQ}_{2}$ & & $\mathrm{EQ}_{1}$ & $\mathrm{EQ}_{2}$ & $\mathrm{EQ}_{1}$ & $\mathrm{EQ}_{2}$ \\
\hline & $\mathrm{CO}(\mathrm{mg} / \mathrm{mc}): 10$ & 0,31 & 0,35 & 0,62 & 0,71 & & 0,31 & 0,36 & 0,63 & 0,72 \\
\hline & $\mathrm{NO}_{\mathrm{x}}(\mu \mathrm{m} / \mathrm{mc}): 250$ & 7,81 & 8,93 & 15,63 & 17,87 & & 7,91 & 9,04 & 15,82 & 18,09 \\
\hline & $\mathrm{SO}_{2}(\mu \mathrm{m} / \mathrm{mc}): 120$ & 3,8 & 4,35 & 7,60 & 8,70 & & 3,85 & 4,40 & 7,70 & 8,80 \\
\hline
\end{tabular}

Table 6. Measurement uncertainty

$\mathrm{EQ}_{1}$ - Equipment $1 ; \mathrm{EQ}_{2}$ - Equipment 2 


\section{Conclusion}

It is important to make a reliable measurement and be able to demonstrate that the result is correct. In order to use the Fourier Transform Infrared spectroscopy, it was necessary to demonstrate the equivalence of results obtained by the methods (new developed method and the existing standard / regulatory method).

In the field of environmental protection, the use of equipment based on FTIR technology is very important, in order to monitor several species of gaseous pollutants, considering that the equipment is reliable and very precise. The use of Continuous Emissions Monitoring System implies the compliance with the performance standards and allows the analysis of complex gases from a physical-chemical point of view. Comprehensive certification provides regulated processes with the assurance that monitoring data from Gasmet - FTIR analyzers will meet or exceed all regulatory requirements across an expanded range of compounds.

It is recommended to use analyzers based on FTIR technology both in conventional monitoring schemes and in the case of accidental pollution, where these analyzers have the ability to identify and quantify new polluting species that can be extremely dangerous to both human health and the biosphere as a whole.

\section{References}

1. L.A. Todd, M. Ramanathan, K. Mottus, Atmospheric Environment 35, 1937-1947 (2001)

2. G., Babut, R.I. Moraru, C. Dura, Quality - Acces to Success Journal 16, 103 - 112 (2015)

3. B. Galle, L. Klemedtsson, B. Bergqvist, M. Ferm Atmospheric Environment 34 4907-4915 (2000)

4. D. Griffith, B. Galle, Atmospheric Environment 34, 1087-1098 (2000)

5. B. Galle, J. Samuelsson, B. Svensson Environ. Sci. Technol. 35, 21-25 (2001)

6. L. Toth, I. Kovacs, A.N. Calamar, G.A. Gaman, E. Ghicioi, Proceedings of the 19th International Multidisciplinary Scientific Geoconference SGEM 2019, 19, 1007-1014 (2019)

7. Directive 2008/50/CE (2008)

8. Standard EN $14626(2012)$

9. Standard EN $14211(2012)$

10. Standard EN 14212 (2012)

11. Continuous Emissions Monitoring System. Available on https://www.gasmet.com/products/category/emission-monitoring-systems/continuous-emissionsmonitoring-system-cems-ii-e/

12. B. Liptak, Process Measurement and Analysis (CRC Press, New York, 2003)

13. V. Barwick (Ed), Eurachem/CITAC Guide: Guide to Quality in Analytical Chemistry: An Aid to Accreditation (3rd ed. 2016). ISBN 978-0-948926-32-7. Available from www.eurachem.org. 